\title{
From LEGO to Arduino: Enhancement of ECE Freshman Design with Prac- tical Applications
}

\section{Dr. Carlotta A. Berry, Rose-Hulman Institute of Technology}

Dr. Carlotta A. Berry is an associate professor in the department of Electrical and Computer Engineering at Rose-Hulman Institute of Technology. She is the director of the multidisciplinary minor in robotics and co-director of the Rose building undergraduate diversity scholarship and professional development program. She has been the President of the Technical Editor Board for the ASEE Computers in Education Journal since 2012. She is a member of ASEE, IEEE, NSBE, and Eta Kappa Nu.

Dr. Daniel Chang, Rose-Hulman Institute of Technology

Prof. Christopher Miller, Rose-Hulman Institute of Technology

Chris is an Assistant Professor of Electrical \& Computer Engineering at Rose-Hulman Institute of Technology. His interests include engineering education, embedded systems, and ubiquitous computing. 


\title{
From LEGO ${ }^{(R)}$ to Arduino: Enhancement of ECE freshman design with practical applications
}

\begin{abstract}
This paper will describe the transition of a highly successful freshman electrical and computer engineering design course in order to improve student learning and mastery. The primary enhancement was to change the hardware platform for the design project from $\mathrm{LEGO}^{(\mathrm{R})}$ MINDSTORMS $^{(\mathrm{R})}$ to Arduino microcontrollers. There were several motivations for this change including creating a stronger emphasis on electrical and computer engineering concepts, improving programming and circuit building skills, and increasing the course technical rigor. The objectives of this course are to introduce students to electrical and computer engineering as well as the engineering design process, teamwork skills, professional development, and technical documentation through a quarter-long design project. A primary focus during the course is also for the students to have fun while learning these things. This year the course was converted to include not just a quarter-long design project but also mini-projects implemented with the Arduinobased SparkFun Inventor Kit. The sample projects in the kit touch upon a variety of ECE topics and help the students create connections with their chosen discipline. The kit is also a great tool for improving their technical skill with respect to hardware and software. This paper will contrast and compare this course before and after the change to microcontrollers in order to verify that the new learning objectives were met and the course was indeed improved. The paper will also review lessons learned in order to improve future iterations of the course.
\end{abstract}

\section{Introduction}

The goal of this paper is to describe how an electrical and computer engineering (ECE) freshman design course was enhanced to include more practical applications by introducing the Arduino Uno microcontroller. A previous iteration of this course has been successfully taught for more than a decade using LEGO $^{(\mathrm{R})}$ MINDSTORMS $^{(\mathrm{R})}$, but recently transitioned to using Arduinos to highlight topics in the ECE discipline earlier in a student's career. The entire course was built around a team-based final design project to create a robotic system to achieve some task or game challenge. In the past, some of the design projects were bowling, basketball, hockey, soccer, building towers, spelling words, and doing math. In addition to design, some of the other objectives of the course were to provide an overview of ECE and teach teamwork and communication skills. Although this course was very successful, the ECE department felt that it was time for a change. The primary motivation for the change was to create design projects to illustrate stronger connections to the student's chosen major as well as encourage a maker spirit. The previous design projects were more mechanical in nature and did not exemplify key concepts from the various branches of electrical and computer engineering. In the previous iteration of the curriculum, students weren't exposed to their discipline until their sophomore year and many did not know what electrical and computer engineers did. One of the primary motivations of this course was to expose students to their major much earlier, which would help with retention. The Arduino 
platform allows the instructors to create projects that will expose the students to concepts they will learn in their respective curriculum earlier in their career. In addition, it will teach the students some valuable skill sets that will be helpful in follow on courses such as DC circuits, introduction to programming, digital systems, and microcontrollers. For example, the students will learn to recognize resistors, capacitors, diodes, transistors and how to build a circuit on a breadboard with them. The key difference between this paper and other recent publications on the topic will be the treatment of how the learning activities integrate into upper level courses in the curriculum.

Due to the large online Arduino community, the authors chose this platform because of the readily available resources at the student's fingertips. These extensive resources allow the students to explore beyond the material taught in class. It was the professors' hope that the students would explore, build, and create projects with the kit beyond those required in class. The SparkFun Inventor's Kit was used for the mini-projects and final project with some modifications to the basic examples to encourage independent and team-based learning. The midterm project involved students learning to solder as they built a component tester that they will use in the rest of the labs in the curriculum. The component tester could measure resistors, inductors, capacitors, transistors, diodes, and serve as a function generator.

The paper will summarize the key learning objectives, mini-projects, midterm, and final project and how they related to the various electrical and computer engineering concepts. There will be a summary of some of the assignments used to encourage reflective learning as well as teamwork such as journals, memos, reports, code, demonstrations and presentations. The course was taught for the first time in Fall 2015 quarter and again in Winter 2015 quarter. There will be a qualitative and quantitative analysis of the learning artifacts in order to identify trends and lessons learned to continue improving the course. There will also be a comparison of the student course evaluations before and after the change to the Arduino Uno microcontroller. These results will be presented in the paper along with recommendations for improvement and future work.

\section{Literature Review}

During the re-design of the ECE freshman design course, a review of relevant courses at other institutions with similar learning objectives was performed. Hendrix et al. proposed the creation of a breadth-first introductory course in electrical and computer engineering at the US Air Force Academy in order to not only motivate students but encourage them to obtain depth knowledge into upper level topics ${ }^{1}$. The motivation for this work was to enable students to distinguish between Electrical Engineering (EE) and Computer Engineering ( $\mathrm{CpE}$ ). In addition, there was a need to increase the students' knowledge of the concentrations in their field such as power systems, communication, electromagnetics, digital signal processing, controls and computer architecture. The goals of the USAF course were to be fun, provide an overview of EE and CpE, breadth before depth, extensive hands-on experience, and introduce software and test equipment. The broad topics in the course were RF communications, RADAR and electronic warfare, analog circuits, and digital circuits. The authors concluded that the updated, flipped classroom built confidence and

intuition and more confidence with standard ECE tools and fundamental ECE principles while also 
encouraging curiosity. The authors found that the primary benefit of the flipped classroom was that they could cover more of the hands-on material.

Ferguson et al. at Rose-Hulman Institute of Technology created a course to introduce students to the design process with a goal-based design project ${ }^{2}$. This course was also used to enable the student to learn and practice team skills. The final project involved the creation of a LEGO® robot to satisfy a Product Design Specification (PDS). The solution to the design project was presented during an end of quarter competition. Some of the course objectives were improving creativity, preparing team documents such as agendas, minutes, memos, making team decisions, organizing and managing a project, preparing a professional development plan, demonstrating ethical behavior, and presenting technical oral and written work. The authors found that the overall response by the students was positive and that they perceived some value in learning teamwork skills as well as design.

The University of Colorado provided a summary of an experiential hands-on design experience that had been shown to improve retention and transfer in their college so they transferred the work to a high school level course ${ }^{3}$. This course introduced various engineering disciplines including mechanical, electrical and computer engineering by using a technical curriculum and hands-on design projects. The high school and college curricula used the SparkFun Inventor's Kit, Simon Tilts soldering kit, and hand tools. The hope was that this course would also be a tool to teach and attract high school students to the field of engineering.

Rosen et al. presented their work on the creation of an Arduino-based racecar project in a firstyear engineering technology course ${ }^{4}$. The purpose of this course was to stimulate students' interest in computer programming, industrial design, and fabrication. The course also provided a handson introduction to topics related to electrical, mechanical, and industrial engineering technology. The robot was made from an Arduino Uno, Adafruit motor shield, sonar, and a chassis fabricated on a 3-D printer. The learning objectives included students being able to create basic computer programs and to design, analyze and fabricate mechanical components. The final project combined theory and practice to help the students become better problem solvers by finding practical solutions to real life problems using a problem-based approach.

Rectenwald and Hall designed a freshman engineering course that included microcontrollers to provide hands-on experiences, applications of engineering principles, training in the programming, and problem solving ${ }^{5}$. In addition, the goal of the course was to motivate and engage the students. The Living with the Lab was a project-based hands-on curriculum that exposed students to robotics, mass and energy balances, dynamics, design, teamwork, electronics, programming, and sensors. The students built a BOE-BOT chassis with an Arduino microcontroller and used it to complete homework that required creating programs. The robot challenge involved principles related to biomedical, chemical, civil, electrical, industrial, mechanical, and nanosystems engineering.

Tian introduced a new engineering design course at Eastern Mennonite University by using the Arduino microcontroller ${ }^{6}$. The course focused on defining the problem, developing a project 
statement, generating and evaluating ideas, leading and managing the process and the outcomes. The course had two projects including a solar-powered cell phone charger and persistence of vision wand.

\section{Method}

Engineering Practice (ECE160) is a two credit hour course that meets four hours per week to allow for lectures and team meetings. The course is only 2 credit hours because there are no exams and most of the course work is completed in class with a team, instructor or teaching assistant help. This model was preferred in order to assist the students with the assignments since there were no pre-requisites.

Three sections were offered in the Fall and one section offered in the Winter quarter. There are approximately 100 ECE majors in the course each school year. Although the course described in this paper has some similarities to the courses described in the literature review, there are some distinct differences. For example, the Arduino Microcontroller is an integral part of all of the assignments as well as the final project. All of the mini-project assignments include some content about key concepts presented as well as connections to courses the students will see later in their academic career. The objective is for the students to learn about

- Concepts in electrical and computer engineering,

- Connections to upper level courses in their major,

- Electronics and systems,

- Programming and circuit building,

- Technical skills such as soldering,

- Various concentrations in electrical and computer engineering,

- Ethics and professional development, and

- Technical documentation and presentation.

The SparkFun Inventor Kit was selected for the new and improved course because there is an extensive online community for SparkFun and Arduino. Since this is a freshman course, it is very important that there are a variety of resources available to help them complete the assignments. The SparkFun Inventor Kit includes sample programs, sample circuit diagrams and schematics, an Arduino Uno microcontroller, sensors, resistors, LEDs, breadboard, buzzer, LCD, pushbutton, keypad, and wireless transceiver. The kit was used for the individual mini-projects as well as the team-based final project. Most of the mini-projects were modifications of the samples provided in the kit in order to give the students a solid foundation on the key concepts while also allowing for some creativity on how they implemented the modification. As part of their submission, the students were required to create a reflective learning journal to address the learning objectives, the new skills learned, their observations, and challenges they faced. The students were also required to submit properly commented code with logical functions, variables, and constants and also perform an in-class demonstration.

The students also completed a midterm project to learn soldering by building a transistor tester kit, which they will use for the remainder of their academic career. This device is used to measure 
transistors, resistors, inductors, capacitors, and diodes and can also be a function generator. As part of their assessment for the midterm project, they were required to recognize, describe, and measure various electric components while also completing a journal entry. The team-based final project was an enhanced version of the popular Simon Electronic Game from the 1980s. The game included extra modes as well as statistics on the liquid crystal display (LCD). The final project was meant to build on prior projects as well as teach teamwork, cooperative learning, and project management with several milestones and demonstration checkpoints. As part of the final project, the teams were required to keep agendas, meeting minutes, and progress memos. The teams also performed group processing, alternating roles, and effective decision making. The final project for Fall 2015 is shown in Figure 1. The term culminated with a final projects competition where the teams used their project to compete in various game rounds. Table 1 summarizes the schedule for the freshman design course as well as connections between the assignments and other courses or concentrations in their discipline.

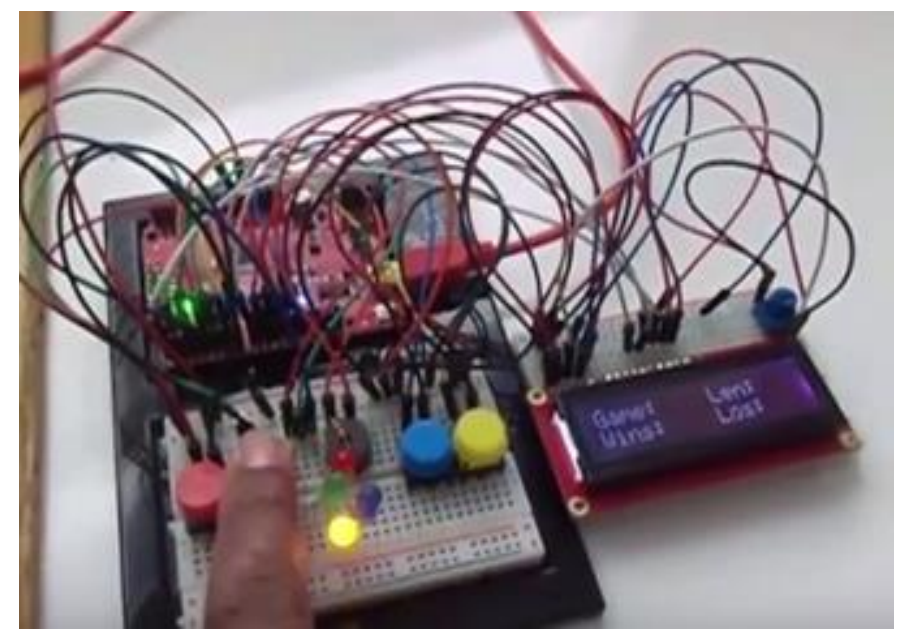

Figure 1: Simon Electronic Memory Game Final Project

One major change from the original version of the course was to add dedicated tutors and a teaching assistant. Due to the increased rigor of the content, the members of the ECE honor society Eta Kappa $\mathrm{Nu}(\mathrm{HKN})$ were enlisted to hold office hours five days a week. In addition, an upperclassmen student was recruited to be an in-class teaching assistant. The teaching assistant helped with debugging projects and grading the mini-projects during class.

The prior version of the course included much more documentation and instruction on the design process with limited technical content. It was assumed that most students could figure out how to use LEGO ${ }^{\circledR}$ MindStorms ${ }^{\circledR}$ with no instruction. Although engineering design and documentation content is extremely important in an engineering curriculum, the professors felt that it was more important for freshmen to become more knowledgeable about their chosen discipline and improve their technical skills to help with the courses they will take in their immediate future. In the previous iteration of the curriculum, students weren't exposed to their discipline until their sophomore year and many did not know what electrical and computer engineers did. 
Table 1: Course Schedule

\begin{tabular}{|l|l|l|}
\hline Week & Topics \& Assignments & Connections \\
\hline 1 & $\begin{array}{l}\text { Design, Testing, Evaluation, Debugging } \\
\text { MP01 - LEDs - for loops, functions, arrays } \\
\text { MP02 - analog and digital Inputs - Pushbuttons } \\
\text { and Potentiometers - Boolean Algebra, conditionals }\end{array}$ & $\begin{array}{l}\text { Circuits, microcontrollers, } \\
\text { programming, digital systems }\end{array}$ \\
\hline 2 & $\begin{array}{l}\text { Creativity and Brainstorming } \\
\text { MP03 - analog and digital Outputs - RGB LED, } \\
\text { piezo buzzer, pulse width modulation } \\
\text { MP04 - sensors and LCDS, software libraries }\end{array}$ & $\begin{array}{l}\text { Circuits, digital systems, } \\
\text { analog electronics, } \\
\text { programming }\end{array}$ \\
\hline 3 & $\begin{array}{l}\text { Professionalism and Ethics } \\
\text { MP05 - object avoidance sensor and DC motors, } \\
\text { transistors, IR reflection } \\
\text { MP06 - servo motors and joysticks, classes, objects }\end{array}$ & $\begin{array}{l}\text { Analog electronics, power, } \\
\text { programming, controls }\end{array}$ \\
\hline 4 & $\begin{array}{l}\text { Cooperative Teams, Documentation } \\
\text { MP07 - keypad and relay } \\
\text { MP08 - Wireless Communication }\end{array}$ & $\begin{array}{l}\text { Digital systems, } \\
\text { communication systems, } \\
\text { antennas, programming }\end{array}$ \\
\hline 5 & Midterm Project - Soldering - Tester Kit & Microcontrollers \\
\hline 6 & Final Project - Simon Says Enhanced & $\begin{array}{l}\text { Integration of all prior } \\
\text { concepts }\end{array}$ \\
\hline 7 & Final Project Work & Design \\
\hline 8 & Final Project Work & Teamwork \\
\hline 9 & Final Project Competition & $\begin{array}{l}\text { Technical documentation } \\
\text { (minutes, agendas, memos) }\end{array}$ \\
\hline 10 & Technical Reports and Presentations & Junior and senior design \\
\hline Finals & Final Project Report \\
Final Project Oral Presentation &
\end{tabular}

One of the primary motivations of this course was to expose students to their discipline earlier, which would help with retention. Another change in the new version was to put more of an emphasis on individual assignments and technical effort before the team-based work. Most of the design content was moved to the junior year, right before the students started senior design. Table 2 shows a summary of the schedule for the prior version of the course. 
Table 2: Prior Version of the Course

\begin{tabular}{|l|l|}
\hline Week & Topics \& Assignment \\
\hline 1 & Engineering Design, Team Assignments and Organization \\
\hline 2 & Team Meetings, Communication, Technology Familiarization and Demonstration \\
\hline 3 & Design Process, Creativity, Project Brainstorming, Product Design Specification \\
\hline 4 & Conceptual Design, Subsystem Identification \\
\hline 5 & Conceptual Capture Report, Design Review Preparation \\
\hline 6 & Testing and Evaluation, Design Reviews \\
\hline 7 & Professionalism \\
\hline 8 & Project Work \\
\hline 9 & Final Project Competition \\
\hline 10 & Technical Reports and Presentations \\
\hline Finals & $\begin{array}{l}\text { Final Project Report } \\
\text { Final Project Oral Presentation }\end{array}$ \\
\hline
\end{tabular}

\section{Results}

The grading scheme for the old course and the new course are shown in Table 3. The primary difference beside the actual assignments is the grade distribution for the individual and team assignments. This change was necessary in order to ensure that each student gained the necessary technical skill to be able to be an active contributor to the team project and be successful in the remainder of their academic career. It is vitally important that every ECE student be able to solder, build circuits, and write basic programs as early as possible in their curriculum. There was also a significant reduction in the amount of documents that the students had to submit. This was necessary due to the higher level of difficulty required to complete the projects.

\section{Quantitative Results}

The quantitative results were obtained by evaluating the individual and team assignments as well as the final course grades for the original course during the Fall 2014 and Winter 2014 quarters and the enhanced course during Fall 2015 and Winter 2015 quarters. Figures 2 and 3 show the demographic distribution of the students in the course during the 2014 and 2015 quarters. It should be noted that sometimes upperclassmen who are advanced in the curriculum are required to take the course during their sophomore year in order to satisfy other course requirements during their freshman year. In addition, some non-ECE majors take this course due to interest or a desire to 
pursue a second major or minor. The mini-project quiz questions are available in the Appendix of the paper.

Table 3: Grading Scale

\begin{tabular}{|l|l|l|l|}
\hline \multicolumn{2}{|c|}{ Original Course } & \multicolumn{2}{c|}{ New Course } \\
\hline Individual Assignments & $\mathbf{4 0 \%}$ & Individual Assignments & $\mathbf{6 0 \%}$ \\
\hline Skills Assessment & & Mini-Projects & \\
\hline Tribot Demo & & Midterm Project & \\
\hline Agendas/Minutes & & Journal & \\
\hline Professional Development Memo & & & \\
\hline Project Design Specification Quiz & & Mini-Project Quizzes & \\
\hline Peer Evaluation & & Peer Evaluation & \\
\hline Participation & & Participation & \\
\hline Final Report Executive Summary & & & \\
\hline Team Assignments & $\mathbf{6 0 \%}$ & Team Assignments & $\mathbf{4 0 \%}$ \\
\hline Final Project & & Final Project & \\
\hline Final Presentation & & Final Presentation & \\
\hline Final Report & & Final Report & \\
\hline Team Data/Kit Inventory Memo & & Memos & \\
\hline PDS Memo & & & \\
\hline Project Strategy \& Functions & & & \\
\hline System Conceptual Capture Report & & & \\
\hline Design Review & & & \\
\hline Test/Verification Plan & & & \\
\hline Lego Kit Return Memo & & & \\
\hline Project Notebook & & Agendas/Minutes & \\
\hline
\end{tabular}




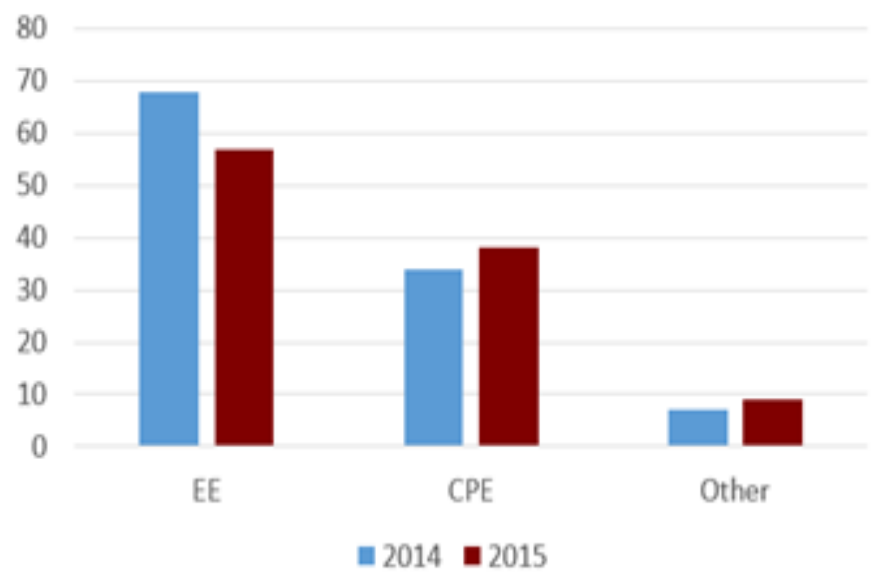

Figure 2: Classification Course Demographics

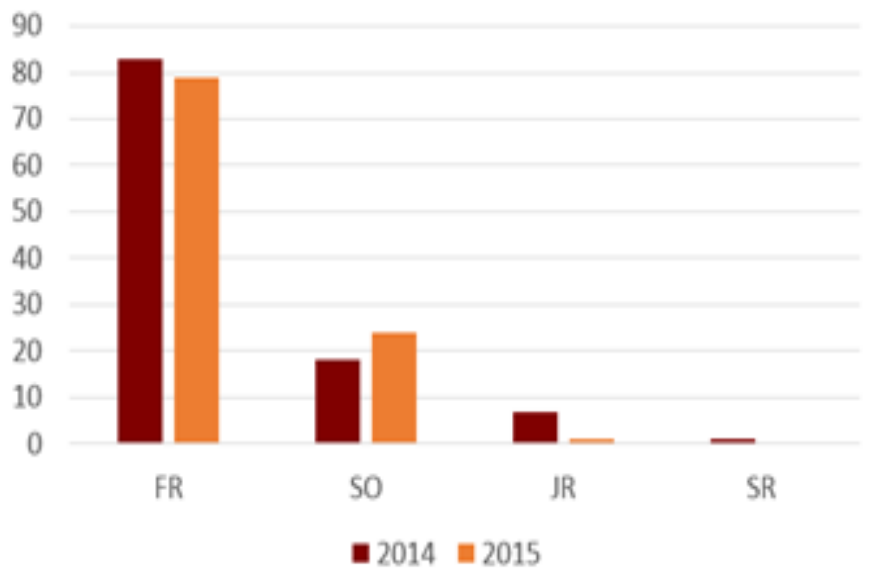

Figure 3: Major Course Demographics

Figure 4 shows the ratings for the end of course evaluations before and after the course update. The individual, group, and overall grades in the course was also examined. The most compelling result is that although the class was significantly harder, there was no significant difference in the grades or the course evaluations with respect to the quality of learning and overall course rating.

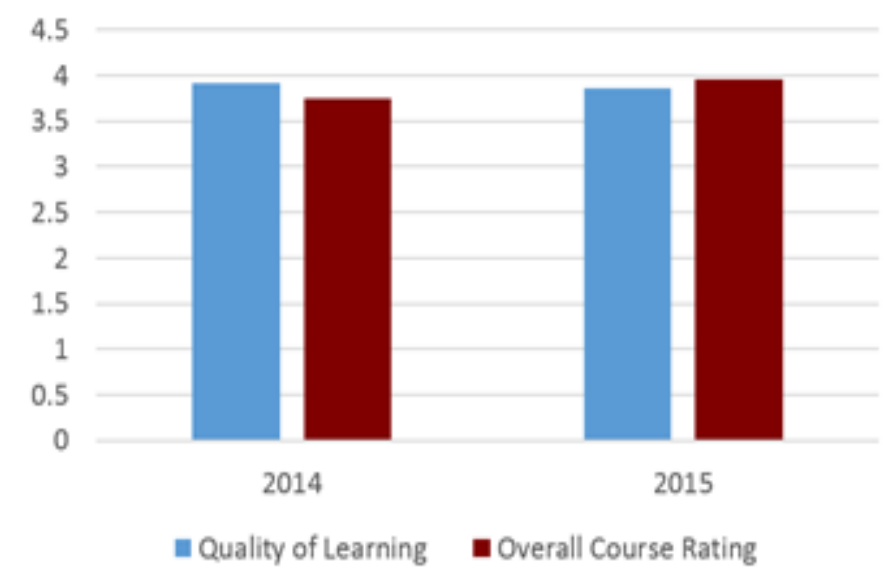

Figure 4: End of Course Evaluations 


\section{Qualitative Results}

The qualitative results of the new class were obtained from the end of course evaluations and feedback from faculty and students during the final project competition and final project oral presentations. A summary of the comments was as follows:

- Some students felt there should have been less explicit instruction such as providing sample circuits and sample code

- Some students felt that there should have been more explicit supplemental instruction on programming and building circuits because they had not done it before

- Some students wanted the robots returned to the course and the final project to be more challenging; and to build more on the mini-projects, while including less explicit instruction

- Some faculty and students wanted the competition rules to be better clarified in order to avoid collusion

- Some students felt that the schedule was too rigorous and there should have been more time between mini-project due dates

- Many students appreciated the integration of microcontrollers into the course and the connections with other courses and what they will learn in the future

- Many students also enjoyed the opportunity to be creative, makers, and tinkerers by keeping the transistor tester kit and SparkFun inventor kit for the rest of their academic career

- In the past, students complained regularly about the shear amount of paper work and documentation in the course and this has now all but disappeared

- In both versions of the course, students consistently stated that they had fun while learning

\section{Impact on Upper Level Curriculum}

The revisions to the course benefit students in their preparation for many later courses in the ECE curriculum. Some of the most direct benefits are for the sophomore-level embedded systems course. In this course, students build microcontroller-based circuits on breadboards, using many of the same types of peripherals as are introduced in the mini-projects, such as pushbuttons, LEDs, potentiometers, motors, servos, LCD displays, and keypads. Thus students are able to develop an abstract understanding of how these devices work and how they integrate with microcontrollers, which will support their development of a deeper understanding of these concepts in embedded systems. In the embedded systems course students are also asked to program in $\mathrm{C}$, however many students had no prior experience with this language. The introduction of Arduino-based projects to the revised course also gives students exposure to a programming language very similar to $\mathrm{C}$. This will help to reduce the barrier for grasping the syntax and basic programming styles used in the later course.

Another course that directly benefits from the student's experience is DC circuits (ECE 203). ECE 203 is a freshman-level introductory electrical engineering course whose prerequisite is the freshman design course described in this paper and is the first foundational electrical engineering 
course an ECE student takes. In this course, students learn about basic electrical concepts such as Ohm's Law, Kirchhoff's Laws, Node Voltage, Mesh Current, Operational Amplifiers, and ends with first order circuits. The students also have a weekly lab period where they build electric circuits on a bread board and take measurements. In the previous iteration of the course, it was likely that a student had never breadboarded an electric circuit before or been exposed to basic electrical engineering concepts. With this new design course, students are introduced to the foundational material of the electrical engineering field earlier, which should translate into success when they take DC circuits.

Students take introduction to software development (CSSE120) during the final quarter of their freshman year. This course is a formal introduction to object-oriented programming by using Python and robots. Topics covered in the course include data types, variables, control structures, arrays, classes, data I/O, and teamwork. The new Engineering Practice course will provide some basic applications of these concepts to assist the students in learning them in context when they later take the programming course.

Lastly, the material taught in the freshman design course should help students with their first computer engineering course, Introduction to Digital Systems (ECE 233). Like ECE 203, ECE 233 is usually the first foundational computer engineering course an ECE student takes. In this course, students learn about basic computer engineering concepts such as binary numbers, logic gates, flip-flops, state machines, designing a digital system such as an arithmetic logic unit (ALU), and basic computer architecture. Like ECE 203, in the past it was quite common for students to have no knowledge of concepts such as binary numbers, logic gates, and bits or even what a computer engineer does for a living. With our new design course, students are now introduced to logical expressions when writing code (such as their If/Else conditionals) and also introduced to setting binary bits to program settings on their microcontroller. This allows the instructors of ECE 233 to now be able to assume that students have at least been introduced to basic computer engineering concepts and gives them the opportunity to better retain students in the field of computer engineering.

\section{Conclusions}

In this paper, we described how a freshmen engineering design course was successfully upgraded to incorporate more technical content and relationships to upper level courses by transitioning from the LEGO® MINDSTORMS® to the Arduino Uno microcontroller. There was no significant different in the course grades, evaluations, or feedback after the change. Some of the primary feedback from the students was to create a more challenging final project and less explicit instruction about how to complete the tasks. In addition, some students requested more supplemental introductory instruction on hardware and software concepts since there was a wide range of skill sets for a first quarter freshman course. In addition, based upon some of the confusion in the final project competition, the faculty requested that some of the original documents should be returned back to the course such as the competition rules quiz and the professional development and ethics memo. One invaluable change made in the new version of 
the course was to use the HKN honor society members as tutors and the addition of an in-class teaching assistant.

Although the students enjoyed the prior version of the course, they are now more challenged and seemed to appreciate the relevance of the new course content to the courses in their immediate future. In addition, some students were extremely overwhelmed during the first two to three weeks of the course because they had never programmed or built a circuit before. However, they quickly came up to speed and by the end all were able to achieve the required learning objectives. One interesting unexpected byproduct of the new course was that more non-ECE majors registered to take the course due to their interest in the topics. It is the authors' hope that the new and improved engineering practice course will serve as a great recruiting tool for majors, second majors, second degrees, and minors.

\section{Future Work}

Based upon feedback from the first offering of this course in Fall 2015, there have been several changes implemented in the current offering of this course during Winter 2015. These changes are summarized in the following list:

- There was an introductory assignment and additional instruction provided at the beginning of the course on programming in Sketch (Arduino-based IDE) as well as the hardware and building circuits on a breadboard.

- The mini-projects were also modified to be more challenging and require the students to think more independently beyond the sample projects.

- The ethics and professional development memo was returned to the course in order to encourage reflection on their future career as a professional and how integrity should become part of every aspect of their life.

- The competition rules quiz was returned to the course in order to resolve issues with confusion about what is and is not allowed during the final project competition.

- The robot was returned to create a more challenging final project. The new robot is a BOEBOT with an Arduino shield and gripper and is shown in Figure 5. The students are able to capitalize on their newly acquired hardware and software skills to design a robotic system with motor control and sensor feedback to achieve some game challenge. This robot and the final project is quite different than the Lego final project and is not moving back to a mechanical system for the following reasons.

- The students are given an assembled robot and are not required to design and build one

- The students are given a variety of sensors and peripherals and they are required to determine how to use them, mount them, and complete the data acquisition or software. For example, they could use infrared or sonar distance sensors. They could also use an IR receiver, wireless receiver, or game controller for remote control 
$\circ$ The students are required to not only create the motion control software but integrate it with the sensor readings for feedback to make decisions

- Some of the preliminary feedback shows that the new final project with the Parallax BOEBOT with gripper, sensors, and peripherals may now be too difficult for this course. The authors will have to explore options for modifying the final project in future iterations of the course.

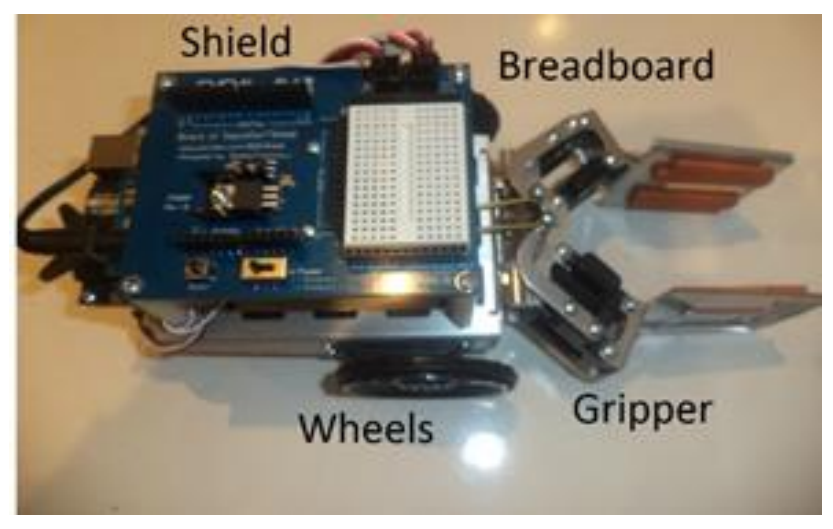

Figure 5: Final Project BOE-BOT

\section{Bibliography}

1. Hendrix, C.D., \& Neebel, D.J. (2014, June). A breadth first course in electrical and computer engineering. Proceedings of the 121st ASEE Annual Conference \& Exposition. Indianapolis, IN.

2. Ferguson, B.A., \& Voltmer, D.R. (2006, June). Engaging ECE Students in the practice of engineering. Proceedings of the $113^{\text {th }}$ ASEE Annual Conference $\&$ Exposition, Chicago, IL.

3. Segil, J.L., Huang, B., Myers, B.A., \& Diamond, L. (2015, June). Porting a University Introduction to Design Course to a Semester Long High School Course Based on Open-source Hardware and Arduino - Evaluation. Proceedings of the 122nd ASEE Annual Conference \& Exposition. Seattle, WA.

4. Rosen, W., Ertekin, Y., \& Carr, M.E. (2014, June). An Autonomous Arduino-based Racecar for First-Year Engineering Technology Students. Proceedings of the 121st ASEE Annual Conference \& Exposition. Indianapolis, IN.

5. Recktenwald, G.W. \& Hall, D.E. (2011, June). Using Arduino as a Platform for Programming, Design, and Measurement in a Freshman Engineering Course. Proceedings of the 118th ASEE Annual Conference \& Exposition, Louisville, KY.

6. Tian, J. (2014, June). A design approach in an Introduction to Engineering course. Proceedings of the 121st ASEE Annual Conference \& Exposition. Indianapolis, IN.

\section{Acknowledgements:}

The authors would like to thank Rockwell Collins for the donation of the SparkFun Inventor's Kits for the entire 2015 freshman ECE class. 


\section{Appendix}

\section{Multiple Choice and True or False Mini-Project Quiz Questions}

\section{Hardware Questions}

1. When you build an electric circuit, why do you put a resistor in series with an LED?

2. When you build an electric circuit, why do you put a resistor connected to $5 \mathrm{~V}$ in series with a pushbutton?

3. If you build a circuit with a potentiometer connected between $0 \mathrm{~V}$ and $5 \mathrm{~V}$, what is the output of the middle pin?

4. A buzzer is considered a digital and analog device because it makes a clicking sound when a constant voltage is applied or produces a tone when a voltage is applied at a certain frequency for a given duration. True or False.

5. In electronics, what is a breadboard used for?

6. A sensor is a device that detects a physical property about the environment such as light or temperature and translates it into a voltage to be used by a microcontroller. True of False.

7. In an electric circuit with a DC motor, what is the purpose of the transistor?

8. In an electric circuit with a DC motor, what is the purpose of the diode?

9. What is the difference between DC and servo motors?

10. When you press a button on a keypad, is represents which type of input?

11. A relay is a mechanical switch with an electromagnet. True or False.

12. Which type of data does a joystick send to the microcontroller?

\section{$\underline{\text { Software Questions }}$}

1. Which of the following lines of code will turn on an LED connected to pin 13 ?

2. Which of the following conditional statements will execute if ONLY button 1 is pressed?

3. In order to make an RGB LED illuminate a red color, which of the following lines of code should you use?

4. What are the benefits of using a software library?

5. Which of the following lines of code will write sensor data to the computer's serial monitor?

6. What is the difference between an object and class in programming?

7. An array is a loop to define several variables at once. True of False.

8. In Sketch programming, which of the following is NOT a variable type? 